\title{
Potential sources of Triatoma infestans reinfesting peridomiciles identified by morphological characterization in Los Llanos, La Rioja, Argentina
}

\author{
María Laura Hernández ${ }^{1 /}$, Jean Pierre Dujardin², David Eladio Gorla1, Silvia Susana Catalá1 \\ ${ }^{1}$ Centro Regional de Investigaciones Científicas y Transferencia Tecnológica, \\ Consejo Nacional de Investigaciones Científicas y Técnicas, Anillaco, La Rioja, Argentina \\ ${ }^{2}$ Institut de Recherche pour le Développement, Centre National de la Recherche Scientifique, Montpellier, France
}

\begin{abstract}
The presence of Triatoma infestans in habitats treated with insecticides constitutes a frequent problem in endemic areas. Basing our study on the hypothesis that descendants of a residual population should be more similar to the pre-treatment population than to any other, we compared the indications of two quantitative morphological approaches. This study seeks to find the origin of $247 \mathrm{~T}$. infestans from three populations found in two chicken coops and a goat corral after treatment with insecticides. The results obtained by quantitative morphology suggest that the $\mathrm{T}$. infestans found between three-34 months after the application of insecticides formed mixed populations with insects derived from residual foci and neighbouring habitats. Our analyses also showed the presence of a phenotype which does not resemble neither the pre-treatment phenotype nor the one from neighbouring populations, suggesting the presence of a particular post-treatment phenotype. The heads size showed some variations in males from different populations and remained unchanged in females, which reinforces the hypothesis of an intraspecific competition for food with priority for females. This article presents, for the first time, the combined analysis of geometric morphometry of heads and antennal phenotypes to identify the composition of reinfesting populations.
\end{abstract}

Key words: Triatoma infestans - reinfesting populations - morphometry - antennal phenotype - peridomicile

Triatoma infestans (Hemiptera: Reduviidae) is a haematophagous insect that is a serious health problem in the southern cone of South America because it is the main transmission vector for Trypanosoma cruzi, the etiological agent of Chagas disease (Lent \& Wigodzinsky 1979, Zeledón 1983). This species is found in rural domestic habitats of impoverished areas of South America, where the vector is common, representing a high risk for the disease transmission. Other habitats frequently infested by T. infestans are chicken coops, goat corrals, rabbit hutches and peridomestic storerooms, which host abundant vector populations a few metres away from dwellings.

Peridomestic areas are important Triatomine shelters, creating potential sources of reinfestation and recolonisation in households and habitats that have been treated with insecticides (Cecere et al. 1997, 2006, Gürtler 1999). The importance of each peridomestic habitat in the process of reinfestation is not clear. Because of their high architectural complexity, peridomestic sites often retain residual or reinfesting populations after a thorough insecticide treatment. In these peridomestic sites, the insecticide does not penetrate deeply into the structure and it degrades more quickly than in the interior of the domicile.

Financial support: FONCYT PICT (2006 878), CONICET MLH, DEG and SSC are supported by the CONICET.

+ Corresponding author: mlhernandez@crilar-conicet.gob.ar

Received 6 July 2012

Accepted 13 November 2012
Los Llanos, in the province of La Rioja, is located south of the Gran Chaco and is one of the most arid and poor regions in Argentina. Within Los Llanos, goat breeding is one of the most important agricultural activities. Goat corrals are popular refuges for peridomestic T. infestans populations because insecticides have low efficacy, leaving residual populations that are able to recover after one or two years (Cecere et al. 1997, Gürtler et al. 2004, Porcasi et al. 2006). The availability of hosts, the peridomestic complexity, the lack of systematic vector control and vigilance, high temperatures in warm seasons and other factors allow for the high peridomestic density of this vector in Los Llanos. The campaigns to control $T$. infestans have not been sustained in this region and because operational responsibility for vector control interventions was transferred from the national government to the provinces in the 1990s, the Chagas programme was interrupted in this endemic area.

After a 15-year interruption of systematic vector control activities by the Chagas Programme, insecticide treatments were resumed in La Rioja province in 2006. Despite these efforts, peridomestic populations frequently reappeared, generating new questions about the risk that they represent for human health. In some cases, there are peridomestic habitats with severe $T$. infestans infestations within a few metres of an intradomestic habitat with low or no infestation. Therefore, each habitat may influence the T. infestans source that invades and successfully colonises nearby habitats, particularly those that are intradomicile. It is of utmost importance to understand the origin of the T. infestans populations that appear in a habitat after insecticide treatments. In places where there 
is neither resistance to pyrethroid insecticides nor wild populations, reinfesting populations may result from errors in insecticide application that leave residual foci or from insects that spread from untreated foci.

Every habitat has a different number and type of host organisms and environmental conditions. These characteristics affect the morphophysiological traits of $T$. infestans in ways that are useful for identifying recolonising insects (Dujardin et al. 1997, López et al. 1999, Catalá \& Dujardin 2001, Schachter-Broide et al. 2004, Abrahan et al. 2008, Hernández et al. 2011). The present study identified the origins of $T$. infestans populations found in two chicken coops and a goat corral that were treated with insecticides. We determined whether $T$. infestans from different post-treatment populations originated from residual foci or emigrated from neighbouring sites. Measurements of head and antennae phenotype similarities were used to test the hypothesis that post-treatment adult $T$. infestans originated from residual individuals. In contrast, if the post-treatment adults were more similar to populations external to the habitat, reinfestations produced the post-treatment populations. It was also possible that both sources, i.e., residual population and reinfestation, contributed to the post-treatment population.

\section{MATERIALS AND METHODS}

Study area - The study was carried out in the department of Independencia in western Los Llanos. This department is located in the southern end of the Gran Chaco Region (arid Chaco) (Fig. 1). Most of the structures proximal to domiciles are chicken coops and goat corrals, which are frequently infested with $T$. infestans. Specimens in both of these habitats were sampled in Patquia Viejo, La Torre and La Aguadita. Patquia Viejo is $570 \mathrm{~m}$ above sea level (masl) and separated by $80 \mathrm{~km}$ from La Torre (1.182 masl). La Aguadita is situated at 900 masl and $60 \mathrm{~km}$ from Patquía Viejo. This locality had only one house with a chicken coop and a goat corral and this home is $5 \mathrm{~km}$ from the nearest population.

The three habitats selected for the study had high levels of infestation before and after treatment with insecticides. The chicken coop in La Torre (chicken coop A) was a $6 \mathrm{~m}^{2}$ structure consisting of branches arranged vertically and intersected by a roof also made of plant material (Fig. 2A). The chicken coop located in La Aguadita (chicken coop B) covered approximately $2 \mathrm{~m}^{2}$ and it was built with wooden walls, plastic fabric, sticks and a roof made of local plant material and leather (Fig. 2B). The third habitat was a goat corral in Patquia Viejo. This habitat comprised a $35 \mathrm{~m}^{2}$ area and was made of a cardboard roof supported by branches from common local shrubs (Fig. 2C).

To select the localities and the habitats where the insect collection was performed, places with a high $T$. infestans infestation after 15 years without insecticide treatments were prioritised. This criterion allowed the largest number of $T$. infestans to be collected for morphometric studies.

All of the habitats selected for study were theoretically high-risk habitats based on the high infestation rate (high infestation rates were found in these locations both pre- and post-treatment) and habitat characteristics supportive of $T$. infestans populations.

Insects - The insects were collected in October 2006 (pre-treatment), January, April and October 2007 and August 2009 (3, 6, 12 and 34 months after insecticide application, respectively). All insects collected after October 2006 were designated as the post-treatment group. In October 2006, the Chagas Provincial Program sprayed the domiciles within the department of Independencia with a concentrated beta-cypermethrin suspension at a nominal dose of $60 \mathrm{mg} / \mathrm{m}^{2}$. The peridomestic structures were not sprayed, but the animals within them were treated with topical formulations of cypermethrin $(6 \%$ active ingredient) on goats and chickens $\left(5 \mathrm{~cm}^{3}\right.$ and 1 $\mathrm{cm}^{3}$ treatment areas, respectively) and fipronil (1\% active ingredient) on dogs.

The habitats (chicken coops A and B and the goat corral) were manually inspected for $30 \mathrm{~min}$ by two experienced persons using a dislodging agent (tetramethrin $0.2 \%$ ) to collect $T$. infestans. On the same pre-treatment date, the neighbouring habitats representing potential sources of $T$. infestans reinfestation (goat corrals, chicken coops, incubating chicken sites and storerooms) were also sampled. In the case of the La Aguadita chicken coop (chicken coop B), the only neighbouring population was a goat corral belonging to the same owner. The

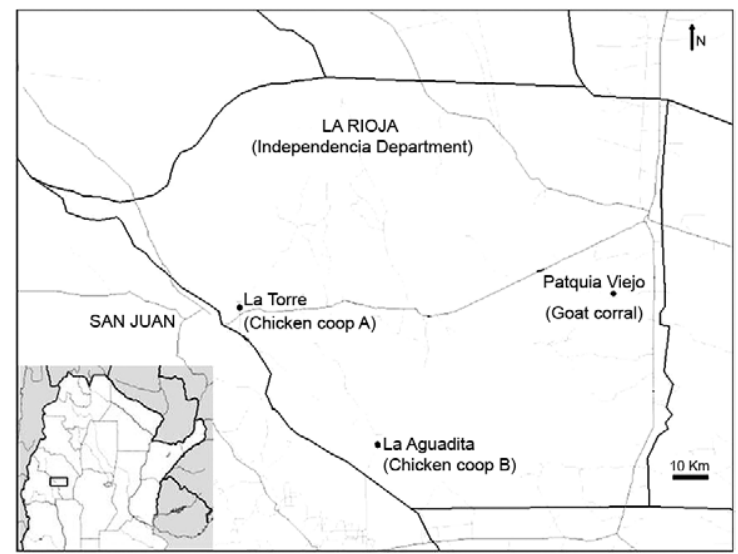

Fig. 1: map of study area showing the locations where the insects were collected (La Torre, La Aguadita and Patquía Viejo) and the habitats selected for study. The inset shows the location of the study area (black box).

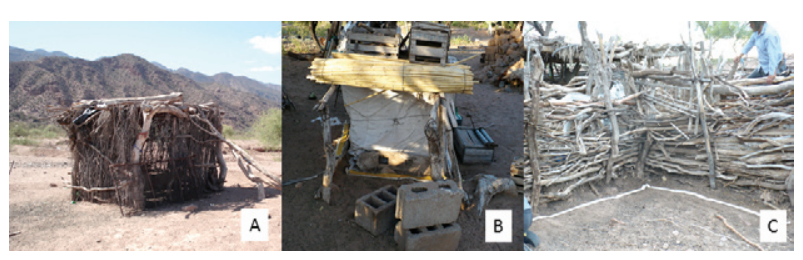

Fig. 2: habitats selected for study. A: chicken coop A; B: chicken coop B; C: goat corral. 
distances between the analysed habitats and the neighbouring habitats ranged from 2-900 $\mathrm{m}$.

Antennal phenotype - The antennae from adult insects were extracted and processed as described previously by Hernández et al. (2011). For each specimen, the ventral side of the pedicel and flagellum 2 were drawn and the sensilla were identified and counted as in Catalá and Schofield (1994). Bristles (BR) from the pedicel, thinwalled (TH) trichoids from the pedicel and flagellum 2 and basiconica (BA) from flagellum 2 were quantified. These receptors were selected because they are associated with dispersal (TH trichoids and BA) and are involved in the olfactory uptake of host or partner odours. The BR (mechanoreceptors) provided information about the insect density in the habitat where the specimens developed as nymphs (Catalá 1993, Catalá \& Schofield 1994). The number of sensilla per segment (antennal phenotype) enabled comparisons between the T. infestans collected pre and post-insecticide treatment for each sex.

The statistical analysis and software used were previously described by Hernández et al. (2011).

Geometric morphometrics of T. infestans heads Each specimen was dissected and preserved in 70\% alcohol for further analysis. Each head was excised at the collar and mounted on a pin attached to a metal support. Photographs were taken through a stereomicroscope (10X magnification) with a digital camera (Kodak C613, 6.2 MP). Ten type II landmarks were selected on the ventral surface of the adult heads, according to Hernández et al. (2011). The average size of landmarks on both sides of the head (5 landmarks for each side) was calculated to reduce intra-individual variation and minimise digitising errors.

The shape variables were obtained by a generalised Procrustes analysis that was subsequently projected into a Euclidean space. Uniform and non-uniform components (e.g., partial warps) (Rohlf 1990) were used as the shape variables. Uniform components describe the global variation due to stretching and compression and non-uniform components correspond to the local variation (Zelditch 2004). These two components describe differences in shape as deviations from an average configuration of landmarks.

When sample sizes were smaller than the number of shape variables, a restricted shape representation, i.e., a set of principal components (relative warps) derived from the shape variables, was used. These relative warps were used as input into a discriminant analysis. The significance in the discriminant analysis was evaluated using the values of Wilks and Mahalanobis distances. These values were evaluated using non-parametric tests based on permutations (5.000 runs). The Bonferroni correction was used for multiple comparisons.

The percentage of phenotypic similarity was calculated using the cross-check test of discriminant analysis. In this test, each individual in the post-treatment population is removed and reinserted into the analysis and they are later assigned into a group according to their phenetic similarity (PAD software).
To compare head size among groups, the isometric size estimator [centroid size (CS)] was derived from coordinates data. This constant is defined as the square root of the sum of squared distances between the centre of the configuration of landmarks and each individual landmark (Bookstein 1991).

The size and shape variables of heads were used to compare pre and post-treatment insects and neighbouring populations by sex and for each habitat. The statistical significance of CS differences was assessed with nonparametric tests based on permutations (5.000 runs).

The relationship between CS and shape discrimination among groups (allometry) was estimated by regression on size variation from the discriminant axes derived from shape.

Bioinformatics - For the morphometric analysis, the modules $\mathrm{COO}, \mathrm{MOG}, \mathrm{COV}$ and PAD were used as described by Hernández et al. (2011). These modules were developed by JP Dujardin and are freely available (mpl. ird.fr/morphometrics).

The STATISTICA package (StatSoft Inc. 2005) was used for the univariate comparisons (parametric ANOVA and Kruskal-Wallis).

\section{RESULTS}

T. infestans captured before and after insecticide treatment in three habitats - Table I summarises the number of $T$. infestans collected in chicken coop A, chicken coop B and the goat corral on different sampling dates. Due to the low number of specimens on post-treatment sampling dates, post-treatment data were aggregated for each habitat.

Adult T. infestans collected post-treatment in chicken $\operatorname{coop} A$ - Antennal phenotypes: univariate analysis of the antennal phenotypes of pre and post-treatment insects revealed significant differences $(p<0.01)$ in all four male sensilla and one female sensilla. The TH of pedicel and multiporous olfactory of pedicel receptors were significantly increased in post-treatment insects. There was also a significant difference $(p<0.01)$ between pre and post-treatment males and females, as determined by discriminant analysis the four antennae variables. The canonical functions 1 and 2 accounted for $79 \%$ and $17 \%$ of the total variation, respectively. Head morphometry size: the average head size of post-treatment insects was significantly smaller than in insects from neighbouring populations $(p<0.05)$, but it did not differ between pre and post-treatment populations. Shape: post-treatment males and females showed significant differences from pre-treatment and neighbouring populations that were independent of size ( $p<0.05$, using the total conformation). Fig. 3B shows the percentage of post-treatment males and females with head-shape phenotypes similar to pre-treatment and neighbouring populations.

Adult T. infestans collected post-treatment in chicken coop $B$ - Antennal phenotypes: univariate analysis of the antennal phenotypes of pre and post-treatment insects showed that there were significant differences ( $p$ $<0.01)$ in one sensillum type in males (F2BA). In fe- 
males, antennal phenotypes were not significantly different. Whereas there was a significant difference $(\mathrm{p}<$ 0.01 ) between pre and post-treatment males, females did not exhibit these differences. The canonical functions 1 and 2 accounted for $72 \%$ and $25 \%$ of the total variation, respectively. Head morphometry - size: head size of post-treatment insects was not significantly different from pre-treatment insects and neighbouring populations. Shape: when the effect of size was excluded posttreatment males did not show significant difference from pre-treatment and neighbouring populations $(\mathrm{p}>0.05$, using the total conformation). Post-treatment female head shapes were not different from the other groups. Fig. 3C shows the percentage of post-treatment males and females with head-shape phenotypes similar to pretreatment and neighbouring populations.

Adult T. infestans collected in the goat corral - Antennal phenotypes: univariate analysis of pre and post-treatment insects revealed significant differences $(p<0.01)$ in both pedicel receptors in males (TH and BR). Females did not show differences in their antennal phenotype. Discriminant analysis with all four antennae variables confirmed that there was a significant difference $(\mathrm{p}<$ 0.01 ) between pre and post-treatment males. Females did not show significant differences between these groups. The canonical functions 1 and 2 accounted for $72 \%$ and $25 \%$ of the total variation, respectively. Head morphometry - size: head size of post-treatment insects showed no significantly different from that of pre-treatment insects and neighbouring populations. Shape: after removing the allometric effect, post treatment males did not show significant difference ( $p>0.05$, using the total conformation). The first two canonical functions account for the $79 \%$ and $21 \%$ of the total variation. Due to the low number of females in one of the groups ( 6 females in pre-treatment), the post-treatment and neighbouring groups were used in the discriminant analysis and the pre-treatment insects were added afterwards as an external group. The post-treatment insects were different from those in neighbouring populations $(\mathrm{p}<0.05)$. Only one factor accounted for $100 \%$ of the variation, with the allometric effect contributing $0 \%$. Fig. $3 \mathrm{~A}$ shows the percentage of post-treatment males and females with headshape phenotypes similar to pre-treatment insects and neighbouring populations.

\section{DISCUSSION}

When $T$. infestans are present in the peridomestic environment a few months after pyrethroid insecticide treatment, it is important to know their origin, the efficacy of the applied treatment and the neighbouring habitats that harbour these triatomines. To identify the origin of $T$. infestans populations, this study analysed the morphology of adult individuals in areas treated with insecticides. Insect head geometric morphometry and antennal phenotype analyses indicated that the T. infestans found three-34 months after insecticide treatments were mixed populations of survivors from the treatment area and the surrounding habitats. A similar result was found

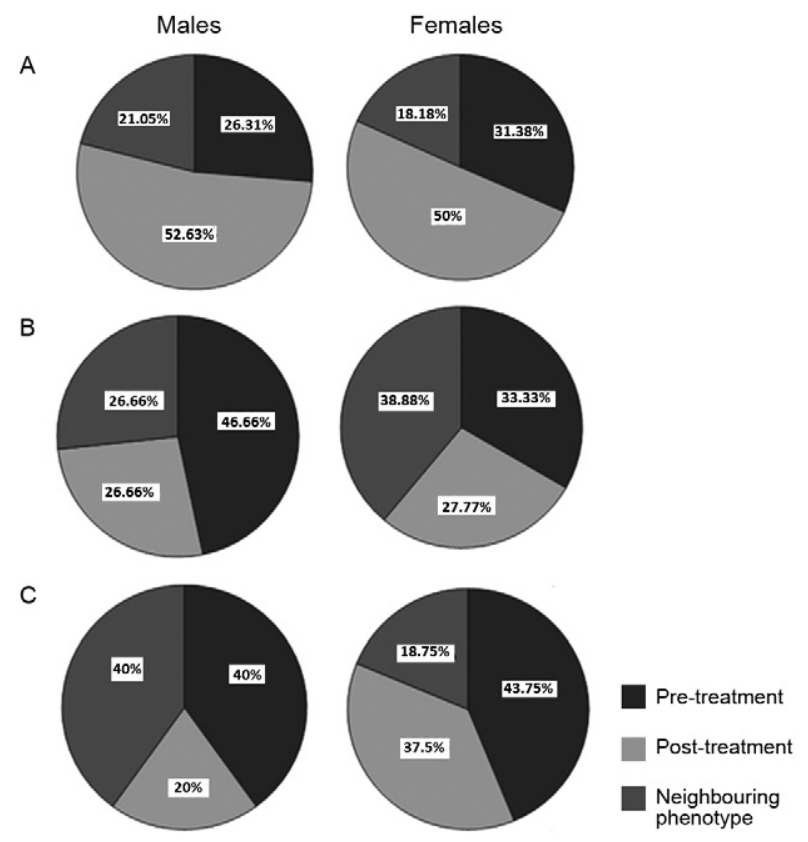

Fig. 3: phenotypic composition of the population of Triatoma infestans after treatment, test based on cross-check, using shape variables of the head. The percentage of pre-treatment phenotype indicates the amount of residual population in this habitat, the percentage of neighbouring populations phenotype indicates the amount of reinfestant phenotype and the percentage of population post treatment indicates the proportion of the population produced by ancient and residual population. A: goat corral; B: chicken coop A; C: chicken coop B.

TABLE I

Adults of Triatoma infestans collected by active search method man-hour

\begin{tabular}{|c|c|c|c|c|c|}
\hline Habitat & Sex & Pre-treatment & $\begin{array}{l}\text { Post-treatment } \\
\text { (3 months) }\end{array}$ & $\begin{array}{l}\text { Post-treatment } \\
\text { (6 months) }\end{array}$ & $\begin{array}{l}\text { Post-treatment } \\
\text { (12 months) }\end{array}$ \\
\hline Chicken coop A & $\begin{array}{l}\text { M } \\
F\end{array}$ & $\begin{array}{l}23 \\
38\end{array}$ & $\begin{array}{l}6 \\
3\end{array}$ & $\begin{array}{c}16 \\
7\end{array}$ & $\begin{array}{l}43 \\
18\end{array}$ \\
\hline Chicken coop B & $\begin{array}{c}\text { M } \\
\mathrm{F}\end{array}$ & $\begin{array}{l}15 \\
12\end{array}$ & $\begin{array}{l}5 \\
1\end{array}$ & $\begin{array}{l}14 \\
10\end{array}$ & $\begin{array}{l}7 \\
8\end{array}$ \\
\hline Goat corral & $\begin{array}{l}\text { M } \\
\text { F }\end{array}$ & $\begin{array}{c}16 \\
5\end{array}$ & $\begin{array}{l}13 \\
16\end{array}$ & $\begin{array}{l}8 \\
5\end{array}$ & $\begin{array}{l}0 \\
2\end{array}$ \\
\hline
\end{tabular}

F: female; M: male. 
when the geometric morphometry of Rhodnius prolixus wings in post-treatment populations was analysed by Feliciangeli et al. (2007); these populations consisted of survivors of the applied insecticide and reinvasions from the sylvatic habitat. Our analysis also discovered phenotypes that differed from both the pre-treatment phenotype and the post-treatment neighbouring populations. This result suggests that a new phenotype originated shortly after the treatment from uncharacterised populations, previous reinfestation populations, residual insects or a combination of all three. Alternatively, the post-treatment phenotype may have originated from genetic derivation or selection due to the insecticide. Reinfestation from wild foci is not likely because sylvatic $T$. infestans have not been detected in light traps or active searches in the study area (G Marti, unpublished observations). However, the classification of insects in the three years post-treatment may have erroneously assigned the sources of reinfestation in the analysed habitats.

The origin of post-treatment $T$. infestans populations and the dynamics of their spread in the Argentine and Bolivian Chaco have been analysed using genetic markers (Pérez de Rosas et al. 2007, Marcet et al. 2008, Quisberth et al. 2011).

These studies suggest that there are genetically similar populations after the vector control and support the residual source hypothesis, as suggested by Dujardin et al. (1997) and Pizarro et al. (2008). However, Marcet et al. (2008) suggested that populations with sporadic control actions were more homogeneous, with the dispersal of $T$. infestans between and within the communities studied.

Phenetic and genetic markers have been widely used to study the population structures and reinfestation dynamics of Chagas disease vectors (Dujardin et al. 1997, Schachter-Broide et al. 2004, Pérez de Rosas et al. 2007, 2008, Abrahan et al. 2008, Marcet et al. 2008, Villacís et al. 2010, Hernández et al. 2011, Quisberth et al. 2011, Gaspe et al. 2012). The correlations between these markers have been verified in triatomines (Dujardin et al. 1999, Villegas et al. 2002, Hernández et al. 2008, Martínez-Hernández et al. 2010, Ceballos et al. 2011, Villacís 2011) and other medically important insects (Dujardin et al. 2004, Bouyer et al. 2007). In some cases, the phenotypic differences observed in triatomines (Moreno et al. 2006) have been subsequently corroborated with genetic markers (Campos et al. 2012). Moreover, Villacís (2011) showed greater microgeographic differentiation of Rhodnius ecuadoriensis populations when antennal phenotypes were used instead of microsatellite markers. This author suggested repetition of the genetic analyzes whit additional primers. Although a pattern of reinfestation was expected in peridomestic habitats, the results show that there was heterogeneity. Each habitat behaved in its own particular manner after the application of insecticide. These differences can result from the variety of construction materials, type and quantity of hosts, level of infestation before insecticide treatment in the habitat and in the neighbouring habitats and $T$. infestans preferences. The two chicken coops contained fewer residual $T$. infestans than the goat corral. The construction materials and design of goat corrals favoured the survival of residual $T$. infestans, as they offered more refuge than the chicken coops. Alternatively, because the insecticide was only applied to adult goats, their offspring (free of insecticidal treatment) may have promoted the growth of residual T. infestans populations in different seasons. Another hypothesis is that that more residual insects emigrated to nearby habitats.

When we compared similar habitats (chicken coops), we observed that the post-treatment females were phenotypically similar to those of the neighbouring populations, suggesting recent reinfestations (chicken coop B) and that the phenotypical differences between these populations were significant, indicating isolation or previous reinfestations that had already produced different phenotypes (chicken coop A).

Lastly, head geometric morphometry and the antennal phenotype analyses were used to determine the origins of $T$. infestans populations reinfesting insecticidetreated habitats. Although both techniques showed the morphological changes that occurred within three years after treatment, different selective pressures forces act on these organs, as observed for heads and wings in Rhodnius pallescens (Caro-Riaño et al. 2009) and in T. infestans (Hernández et al. 2011). The allometry-independent shape analysis of heads detected phenotype variations due to genetic components, whereas the antennal phenotypes showed both genetic variations and environmental adaptations. Thus, antennal phenotypes showed evidence of faster population changes. As shown in Table II, the antennae changed even when the head conformation manifested little or no differences between populations. The converse was not observed, i.e., any change in the heads also appeared in the antennas. Both techniques showed a common result: post-treatment populations arose mainly from residual populations with some input from $T$. infestans in neighbouring peridomestic habitats.

The CS of the heads, which mainly reflects environmental variations, showed some variation in males from different populations, but was unchanged in females. This result supports the hypothesis that intraspecies competition for food compels females to feed themselves independently from the host or the availability of blood in the habitat.

During the last sampling at 34 months after the insecticide applications, the domiciles studied contained only one adult male T. infestans (Hernández 2012). T. infestans may prefer peridomestic habitats, where the movement of individuals preferentially occurs. There may also be little vector exchange via active dispersal between peri and intradomestic habitats, as shown by Ceballos et al. (2005), Vazquez-Prokopec et al. (2006) and Abrahan et al. (2011).

In this study, we found evidence for more extensive movement of males between peridomestic habitats. According to Hernández (2012), the chances of dispersal are not equal in both sexes, as the males appear to have less spatial structure regarding their habitats and enhanced probabilities of dispersal due to flight. However, previous work (Hernández et al. 2011) in a similar study area showed a greater population structure of males between habitats. The dispersal pattern may change in 
time and space, as T. infestans populations behave differently even in nearby geographic areas and in similar habitats. This dispersal pattern can be influenced by the particular environment, history of spraying, nutritional status of the population at the time of sampling, degree of infestation and season, among other factors.

This novel analysis combined head geometric morphometry and antennal phenotypes to identify reinfesting populations, thus reinforcing the utility of these inexpensive techniques to evaluate reinfestation sources.

\section{ACKNOWLEDGEMENTS}

To Ivana Amelotti, Luciana Abrahan, Natalia Folguera and Elmer Rodriguez, for their help in collecting and processing the material.

\section{REFERENCES}

Abrahan LB, Gorla DE, Catalá SS 2011. Dispersal of Triatoma infestans and other Triatominae species in the arid Chaco of Argentina - Flying, walking or passive carriage? The importance of walking females. Mem Inst Oswaldo Cruz 106: 232-239.

Abrahan LB, Hernández ML, Gorla DE, Catalá SS 2008. Phenotypic diversity of Triatoma infestans at the microgeographic level in the Gran Chaco of Argentina and the Andean Valleys of Bolivia. J Med Entomol 45: 660-666.

Bookstein F 1991. Thin-plate splines and the atlas problem for biomedical images. In ACF Colchester, DJ Hawkes (eds.), Information processing in medical imaging Springer-Verlag, Wye, p. 326-342.

Bouyer J, Raver S, Dujardin JP, de Meeus T, Vial L, Thévenon S, Guerrini L, Sidibé I, Solano P 2007. Population structure of Glossina palpalis gambiensis (Diptera: Glossinidae) according to landscape fragmentation in the Mouhoun River, Burkina Faso. $J$ Med Entomol 44: 788-795.

Campos C, Botto-Mahan C, Coronado X, Catalá S, Solari A 2012. Phylogenetic relationships among species of the Spinolai complex and others species of the Triatomini tribe based on mitochondrial DNA sequences (Hemiptera: Reduviidae). Vector Borne Zoonotic Dis doi: 10.1089/vbz.2011.0954.

Caro-Riaño H, Jaramillo N, Dujardin JP 2009. Growth changes in Rhodnius pallescens under simulated domestic and sylvatic conditions. Infect Genet Evol 9: 162-168.

Catalá S 1993. Transmisión vectorial de Trypanosoma cruzi. ¿Define el hospedador su propio riesgo de infección? Medicina 23: 27-28.

Catalá S, Dujardin JP 2001. Antennal sensilla patterns indicate geographic and ecotopic variability among Triatoma infestans (Hemiptera: Reduviidae) populations. J Med Entomol 38: 423-428.

Catalá S, Schofield C 1994. Antennal sensilla of Rhodnius. J Morphol 219: 193-203.

Ceballos LA, Piccinali RV, Marcet PL, Vazquez-Prokopec GM, Cardinal MV, Schachter-Broide J, Dujardin JP, Dotson EM, Kitron U, Gürtler RE 2011. Hidden sylvatic foci of the main vector of Chagas disease Triatoma infestans: threats to the vector elimination campaign? PLoS Negl Trop Dis 5: e1365.

Ceballos LA, Vazquez-Prokopec GM, Cecere MC, Marcet PL, Gürtler RE 2005. Feeding rates, nutritional status and flight dispersal potential of peridomestic populations of Triatoma infestans in rural northwestern Argentina. Acta Trop 95: 149-159.

Cecere MC, Gürtler R, Canale D, Chuit R, Cohen J 1997. The role of the peridomiciliary area in the elimination of Triatoma infestans from rural Argentine communities. Rev Panam Salud Publica 1: 273-279. 
Cecere MC, Vazquez-Prokopec G, Gürtler R, Kitron U 2006. Reinfestation sources for Chagas disease vector, Triatoma infestans, Argentina. Emerg Infect Dis 12: 1096-1102.

Dujardin JP, Bermudez H, Schofield CJ 1997. The use of morphometrics in entomological surveillance of sylvatic foci of Triatoma infestans in Bolivia. Acta Trop 66: 145-153.

Dujardin JP, Chavez T, Moreno JM, Machane M, Noireau F, Schofield CJ 1999. Comparison of isoenzyme electrophoresis and morphometric analysis for phylogenetic reconstruction of the Rhodniini (Hemiptera: Reduviidae: Triatominae). J Med Entomol 36: 653-659.

Dujardin JP, Le Pont F, Martinez E 2004. Is Lutzomyia serrana (Diptera, Psychodidae, Phlebotominae) presente in Ecuador? Parasite 11: 211-217.

Feliciangeli MD, Sanchez-Martín M, Marrero R, Davies C, Dujardin JP 2007. Morphometric evidence for a possible role of Rhodnius prolixus from palm trees in house re-infestation in the state of Barinas (Venezuela). Acta Trop 101: 169-177.

Gaspe MS, Schachter-Broide J, Gurevitz JM, Kitron U, Gütler RE, Dujardin JP 2012. Microgeographic spatial structuring of Triatoma infestans (Hemiptera: Reduviidae) populations using wing geometric morphometry in the Argentine Chaco. J Med Entomol 49: 504-514.

Gürtler RE 1999. Control campaigns against Triatoma infestans in a rural community of northwestern Argentina. Medicina 59: 47-54.

Gürtler RE, Canale DM, Spillmann C, Stariolo R, Salomón OD, Blanco S, Segura EL 2004. Effectiveness of residual spraying of peridomestic ecotopes with deltamethrin and permethrin on Triatoma infestans in rural western Argentina: a district-wide randomized trial. Bull World Health Organ 82: 196-205.

Hernández ML 2012. Efecto del tratamiento con insecticidas sobre la estructuración de las poblaciones de Triatoma infestans (Hemiptera, Reduviidae) en distintos hábitats de Los Llanos de La Rioja, PhD Thesis, Universidad Nacional de Córdoba, Córdoba, $155 \mathrm{pp}$.

Hernández ML, Abrahan L, Dujardin JP, Gorla DE, Catalá S 2011. Phenotypic variability and population structure of peridomestic Triatoma infestans in rural areas of the arid Chaco (Western Argentina): spatial influence of macro and microhabitats. Vector Borne Zoonotic Dis 11: 503-513.

Hernández ML, Abrahan L, Moreno M, Gorla DE, Catalá S 2008. Phenotypic variability associated to genomic changes in the main vector of Chagas disease in the southern cone of South America. Acta Trop 106: 60-67.

Lent H, Wygodzinsky P 1979. Revision of the Triatominae (Hemiptera, Reduviidae) and their significance as vectors of Chagas disease. Bull Am Mus Nat Hist 163: 1-520.

López A, Crocco L, Morales G, Catalá S 1999. Feeding frequency and nutritional status of peridomestic populations of Triatoma infestans from Argentina. Acta Trop 73: 275-281.

Marcet PL, Mora MS, Cutrera AP, Jones L, Gürtler RE, Kitron U, Dotson EM 2008. Genetic structure of Triatoma infestans populations in rural villages of Santiago del Estero, northern Argentina. Infect Genet Evol 8: 835-846.

Martínez-Hernández F, Martínez-Ibarra JA, Catalá S, Villalobos G, de la Torre P, Laclette JP, Alejandre-Aguilar R, Espinoza B
2010. Natural crossbreeding between sympatric species of the Phyllosoma Complex (Insecta: Hemiptera: Reduviidae) indicate the existence of only one species with morphologic and genetic variations. Am J Trop Med Hyg 82: 74-82.

Moreno ML, Gorla DE, Catalá S 2006. Association between antennal phenotype, wing polymorphism and sex in the genus Mepraia (Reduviidae: Triatominae). Infect Genet Evol 6: 228-234.

Pérez de Rosas AR, Segura EL, Fichera L, García BA 2008. Macrogeographic and microgeographic genetic structure of the Chagas disease vector Triatoma infestans (Hemiptera: Reduviidae) from Catamarca, Argentina. Genetica 133: 247-260.

Pérez de Rosas AR, Segura EL, García BA 2007. Microsatellite analysis of genetic structure in natural Triatoma infestans (Hemiptera: Reduviidae) populations from Argentina: its implication in assessing the effectiveness of Chagas disease vector control programmes. Mol Ecol 16: 1401-1412.

Pizarro JC, Gilligan LM, Stevens L 2008. Microsatellites reveal a high population structure in Triatoma infestans from Chuquisaca, Bolivia. PLoS Negl Trop Dis 2: e202.

Porcasi X, Catalá S, Hrellac H, Scavuzzo M, Gorla DE 2006. Infestation of rural houses by Triatoma infestans (Hemiptera: Reduviidae) in Southern Area of Gran Chaco in Argentina. J Med Entomol 43: 1060-1067.

Quisberth S, Waleckx E, Monje M, Chang B, Noireau F, Brenière SF 2011. "Andean" and "non-Andean" ITS-2 and mtCytB haplotypes of Triatoma infestans are observed in the Gran Chaco (Bolivia): population genetics and the origin of reinfestation. Infect Genet Evol 11: 1006-1014.

Rohlf FJ 1990. Rotational fit (Procrustes) methods. In FJ Rohlf, FL Bookstein (eds.), Proceedings of the Michigan morphometrics workshop, University of Michigan Museums, Ann Arbor, p. 27-236.

Schachter-Broide J, Dujardin JP, Kitron U, Gurtler R 2004. Spatial structuring of Triatoma infestans (Hemiptera, Reduviidae) populations from northwestern Argentina using Wing geometric morphometry. J Med Entomol 41: 643-649.

Vazquez-Prokopec GM, Ceballos LA, Marcet PL, Cecere MC, Cardinal MV, Kitron U, Gürtler RE 2006. Seasonal variations in active dispersal of natural populations of Triatoma infestans in rural north-western Argentina. Med Vet Entomol 20: 1-6.

Villacís AG 2011. Análisis de variabilidad fenotipica y diversidad genética de poblaciones sinantrópicas y silvestres de Rhodnius ecuadoriensis (Lent \& Leon, 1958) en dos provincias endémicas para la enfermedad de Chagas en Ecuador, PhD Thesis, Pontificia Universidad Católica de Ecuador, Quito, 328 pp.

Villacís AG, Grijalva MJ, Catalá S 2010. Phenotypic variability of Rhodnius ecuadoriensis populations at the Ecuadorian Central and southern Andean Region. J Med Entomol 47: 1034-1043.

Villegas J, Feliciangeli MD, Dujardin JP 2002. Wing shape divergence between Rhodnius prolixus from Cojedes (Venezuela) and Rhodnius robustus from Mérida (Venezuela). Infect Genet Evol 2: $121-128$.

Zelditch M 2004. Geometric morphometrics for biologists: a primer, Academic Press/Elsevier, San Diego, 443 pp.

Zeledón R 1983. Vectores de la enfermedad de Chagas y sus características ecofisiológicas. Interciencia 8: 384-395. 